\title{
Acute Kidney Injury in a Patient With Cryoglobulinemia Secondary to Hepatic Mucosa- Associated Lymphoid Tissue Lymphoma: Case Report and Literature Review
}

\author{
Artsiom Klimko $^{1}$, Georgiana A. Toma ${ }^{2}$, Nona Bejinariu ${ }^{3}$, Silviu-Mihai Secareanu ${ }^{4}$, Iuliana Andreiana ${ }^{5,4}$ \\ 1. Division of Physiology and Neuroscience, University of Medicine and Pharmacy "Carol Davila", Bucharest, ROU 2. \\ General Medicine, University of Medicine, Pharmacy, Science, and Technology of Târgu Mureş, Târgu Mureş, ROU 3. \\ Department of Pathology, Santomar Oncodiagnostic, Cluj-Napoca, ROU 4. Department of Nephrology and Dialysis, \\ "Dr. Carol Davila" Teaching Hospital of Nephrology, Bucharest, ROU 5. Department of Internal Medicine and \\ Nephrology, University of Medicine and Pharmacy "Carol Davila", Bucharest, ROU
}

Corresponding author: Iuliana Andreiana, iuliana.andreiana@umfcd.ro

\begin{abstract}
We report a patient with IgM-predominant type I cryoglobulinemia (CG), who presented to our nephrology department with acute kidney injury. He was previously diagnosed with sensorimotor neuropathy, which was in remission with maintenance dose of corticosteroids. Upon admission, there were ulcerated, necrotic cutaneous lesions localized to the inner aspect of the thighs bilaterally. Further workup revealed a mucosaassociated lymphoid tissue lymphoma, causing type I CG. Screening tests for hepatitis viruses were negative at this time. Under treatment with diuretics and high-potency glucocorticoids, the patient had an acceptable recovery of renal function and was referred to oncology for treatment. Unfortunately, three months later the patient succumbed to fulminant hepatitis, presumably secondary to reactivation of an occult hepatitis B/D co-infection. We further conducted a literature review to better describe patient characteristics and renal involvement in type I CG.
\end{abstract}

Received 08/31/2020

Review began 09/04/2020 Review ended 09/05/2020 Published 09/14/2020

() Copyright 2020 Klimko et al. This is an open access article distributed under the terms of the Creative Commons Attribution License CC-BY 4.0., which permits unrestricted use, distribution, and reproduction in any medium, provided the original author and source are credited.
Categories: Nephrology

Keywords: maltoma, mucosa-associated lymphoid tissue, lymphoma, cryoglobulinemia, membranoproliferative glomerulonephritis, renal involvement

\section{Introduction}

Cryoglobulinemia (CG) is characterized by immunoglobulin (Ig), which reversibly precipitates at low temperature $\left(<37^{\circ} \mathrm{C}\right)$. The most commonly used classification of CG was proposed by Brouet et al. in 1974 and divides this pathology into three types based on immunochemical properties of the precipitated Ig [1]. Type I cryoglobulins are formed by isolated monoclonal Ig, and etiologies are closely linked to a specific Ig fraction - immunoglobulin M (IgM) is associated with Waldenstrom macroglobulinemia (WM), while immunoglobulin $\mathrm{G}$ (IgG) can be caused by multiple myeloma (MM), monoclonal gammopathy of undetermined significance (MGUS), B-cell non-Hodgkin's lymphoma (B-NHL), or leukemia. Type II and III cryoglobulins are also called mixed as the precipitating Ig is a mixture of mono- and polyclonal Igs, and over $80 \%$ of cases are driven by an infectious etiology - classically, chronic hepatitis C virus (HCV) [2].

The exact pathogenesis of CG is unclear and multifaceted, likely involving environmental triggers, polygenic host susceptibility, and aberrant autoantibody production [3]. Clinically, high levels of circulating Ig cause hyperviscosity, while aggregates of cryoprecipitate obstruct vasculature causing multisystemic ischemic lesions, as was seen in our patient [4]. Renal involvement usually manifests in the form of membranoproliferative glomerulonephritis (MPGN) and has a variable course. Our objective is to discuss renal involvement in type I CG through presenting a case of type I CG that was caused by a primary hepatic mucosa-associated lymphoid tissue (MALT) lymphoma and manifested with acute kidney injury (AKI), sensorimotor neuropathy, and ulcero-necrotic cutaneous lesions.

\section{Case Presentation}

A 58-year-old man presented to our nephrology department with chief complaints of oliguria, lower extremity edema, and resting dyspnea that had increase in severity over the past five days. A year earlier the patient was hospitalized for severe pain and paresthesia in the lower limbs, which led to the diagnosis of axonal sensorimotor polyneuropathy via nerve conduction studies (24.4\% reduction in conduction velocity). Physical examination during this admission revealed an afebrile, jaundiced patient with several ulceronecrotic lesions localized to the inner aspect of the thighs bilaterally (Figure 1). There was a dullness on percussion of the lower right hemithorax, with an absent vesicular sound at this level. Blood pressure was 140/90 $\mathrm{mmHg}$, heart rate 70 beats per minute, no abnormal heart sounds were present, and there was a regular apex beat. 


\section{Cureus}
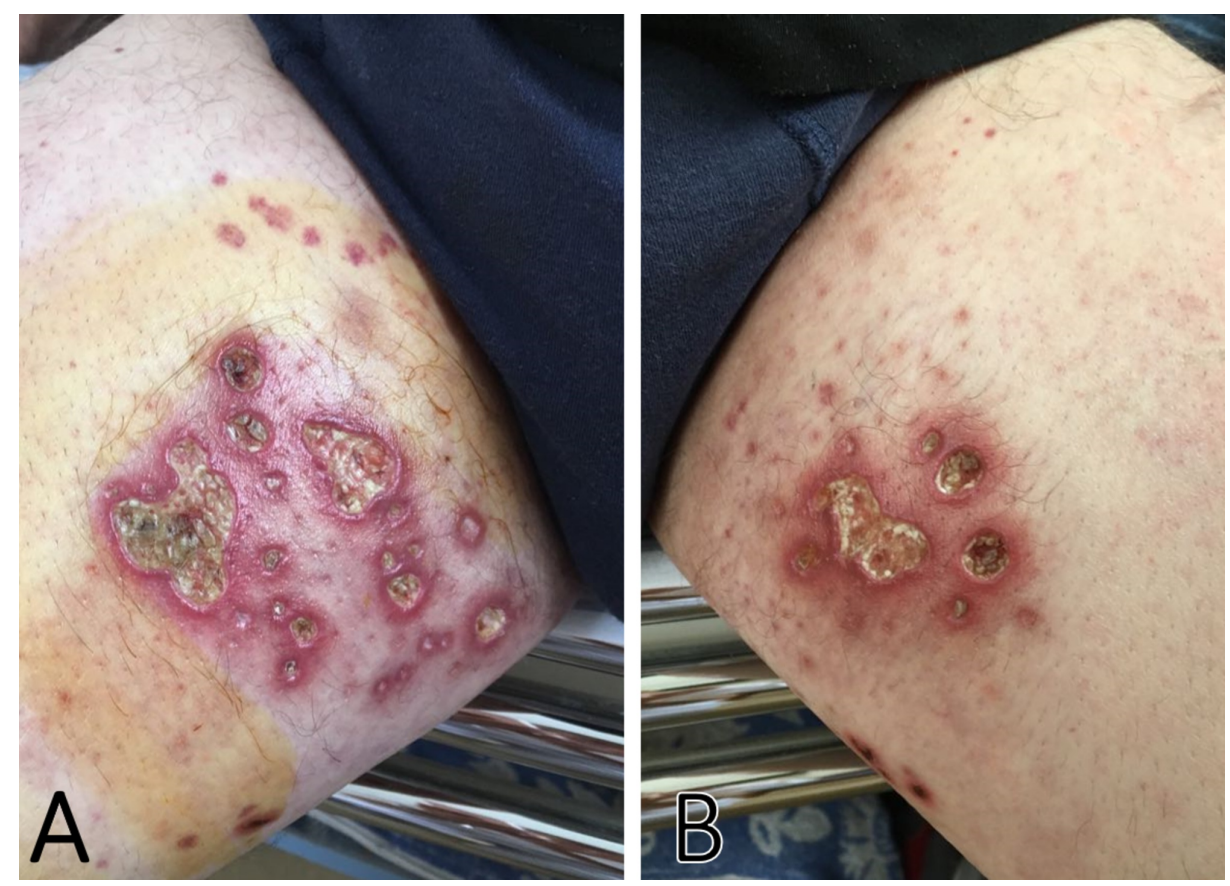

FIGURE 1: Cutaneous lesions with ulceration and necrosis that were present on the left $(A)$ and right $(B)$ legs of the patient upon admission.

The patient's lab results are presented in Table 1 . Elevated creatinine $(2.7 \mathrm{mg} / \mathrm{dL}$ versus $0.9 \mathrm{mg} / \mathrm{dL}$ that was noted one month prior) and urea confirmed AKI. Transaminases with conjugated bilirubin were moderately elevated in a background of negative serology for hepatitis B virus (HBV), HCV, and human immunodeficiency virus (HIV). IgM was almost double the upper limit of normal, while complement (C3/C4) was decreased. Rheumatoid factor, cryoglobulins, and serum viscosity were increased. Urinary light chain kappa concentrations were severely elevated. Serum protein electrophoresis revealed mild increases in alpha-1 globulins (0.3) with all other bands being within reference range. Critical for the workup of the cutaneous vasculitis, antineutrophil cytoplasmic antibodies and antinuclear antibodies were negative.

\begin{tabular}{|c|c|c|}
\hline Lab values & Reference ranges & Patient values on admission \\
\hline \multicolumn{3}{|l|}{ Complete blood count } \\
\hline Hemoglobin (g/dL) & 13-17.5 & 11.5 \\
\hline WBCs (x 10^9/L) & 4-10 & 6.3 \\
\hline Platelet count (x 10^9/L) & $150-400$ & 96 \\
\hline \multicolumn{3}{|l|}{ Biochemistry } \\
\hline Serum albumin (g/dL) & $3.4-5.4$ & 2.8 \\
\hline Serum protein (g/dL) & $6-8$ & 5.2 \\
\hline Urea (mg/dL) & $8-21$ & 131 \\
\hline Serum creatinine (mg/dL) & $0.84-1.21$ & 2.7 \\
\hline Uric acid (mg/dL) & $4.0-8.5$ & 15.0 \\
\hline Aspartate aminotransferase (U/L) & $5-30$ & 424 \\
\hline Alanine aminotransferase (U/L) & $5-30$ & 296 \\
\hline Gamma glutamyl transferase (UL) & $6-50$ & 105 \\
\hline Conjugated bilirubin (mg/dL) & $<0.3$ & 2.71 \\
\hline Total bilirubin (mg/dL) & 0.1 to 1.2 & 4.59 \\
\hline Prothrombin time (seconds) & $11-14$ & 78 \\
\hline
\end{tabular}




\section{Cureus}

Immunology and inflammation

\begin{tabular}{|c|c|c|}
\hline $\lg A(g / L)$ & $0.80-4.0$ & 1.15 \\
\hline $\lg M(g / L)$ & $0.50-2.0$ & 5.2 \\
\hline $\lg G(g / L)$ & $6.0-16.0$ & 8.0 \\
\hline C3 (g/L) & $0.08-0.16$ & 0.67 \\
\hline C4 (g/L) & $0.012-0.042$ & 0.01 \\
\hline Fibrinogen (g/L) & $1.8-4$ & 43.4 \\
\hline C-reactive protein (mg/L) & $<5$ & 45 \\
\hline HBs antigen & Negative & Negative \\
\hline Anti-HCV antibodies & Negative & Negative \\
\hline HIV antibodies & Negative & Negative \\
\hline Antinuclear antibodies & Negative & Negative (low titer) \\
\hline Cytoplasmic anti-neutrophil antibodies (IU/mL) & $\leq 1.9$ & 0.03 \\
\hline Perinuclear anti-neutrophil cytoplasmic antibodies (IU/mL) & $<3.5$ & 0.11 \\
\hline Lactate dehydrogenase (U/L) & $50-150$ & 299 \\
\hline Anti-double stranded DNA (IU/mL) & $<30.0$ & 14 \\
\hline Rheumatoid factor (IU/mL) & $<25$ & 12 \\
\hline Cryoglobulins & NAs & +++ \\
\hline Serum viscosity (cP) & $<1.5$ & 1.8 \\
\hline \multicolumn{3}{|l|}{ Electrolytes } \\
\hline Sodium (mg/dL) & 135-145 & 130 \\
\hline Potassium (mg/dL) & $3.5-5$ & 4.15 \\
\hline Calcium (mg/dL) & $8.5-10.2$ & 4.0 \\
\hline Magnesium (mg/dL) & $1.5-2$ & 2.1 \\
\hline Phosphate (mg/dL) & 3.4 to 4.5 & 5 \\
\hline \multicolumn{3}{|l|}{ Urinalysis } \\
\hline Proteinuria (g/24h) & $\leq 0.15$ & 1.05 \\
\hline Kappa light chains & 0.33-1.94 & 29.6 \\
\hline Lambda light chains & $0.57-2.63$ & 2.2 \\
\hline Kappa/Lambda report & $0.26-1.65$ & 13.3 \\
\hline
\end{tabular}

\section{TABLE 1: Lab results at admission.}

WBC: white blood cells; RBC: red blood cells; HPF: high powered field; Ig: immunoglobulin; HBs: hepatitis B surface antigen; HCV: hepatitiv C virus; HIV: human immunodeficiency virus; DNA: deoxyribonucleic acid.

On abdominal ultrasound, both left and right kidneys were of normal size with no calcifications. Hepatic ultrasonography revealed two lesions (Figure 2). The first mass was localized to the sixth and seventh segment of the right hepatic lobe, measuring $7.2 \times 5.8 \mathrm{~cm}$, and the second mass was localized to the sixth segment of the left hepatic lobe, measuring $9.8 \times 6.8 \mathrm{~cm}$. Both lesions were heterogenous, hypoechogenic, and presented with absent Doppler signs. Esophagogastroduodenoscopy and colonoscopy did not reveal any abnormalities, except mild reflux esophagitis. The workup for the chronic axonal neuropathy included ruling out vitamin deficiencies, infection (HIV, Borrelia), connective tissue diseases (Sjogren, systemic lupus erythematosus, rheumatoid arthritis), metabolic (diabetes), paraneoplastic (lung cancer), and endocrine 


\section{Cureus}

diseases (hypothyroidism).
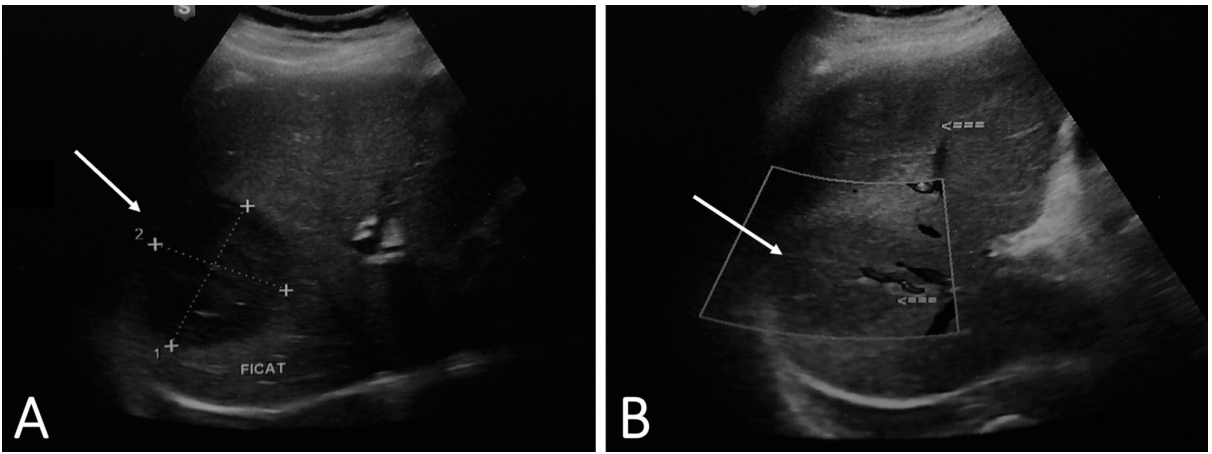

FIGURE 2: Ultrasonography of the liver showing masses (arrow) in the right (A) and left hepatic lobes (B).

At this point, there was a high suspicion for chronic viral hepatitis-induced hepatocarcinoma leading to type III CG; however, the negative viral titers failed to corroborate this trail of thought. The absence of significant hematuria and proteinuria also excluded vasculitis as the cause of the AKI. Given the elevated urinary light chains a hematologic neoplasia with monoclonal gammopathy was, therefore, suspected as being the cause of the neuropathy and the cutaneous vasculitis.

The patient was started on diuretics (intermittent furosemide, $240 \mathrm{mg} /$ day intravenous) and received plasmapharesis for three days. Pulsed therapy with prednisone (240 mg/day, five days total) was started on the third day of hospitalization and was replaced with methylprednisone on day nine. On day three, hepatic and dermal biopsies were also done - unfortunately, a renal biopsy could not be done at this time. On hepatic biopsy, the histopathologic and immunohistochemical findings demonstrated lymphoid cells that stained positive for cluster of differentiation (CD)3, CD5, CD10, CD20, B-cell lymphoma-2, among other markers (Figure 3). The biopsy results cemented the diagnosis of a primary hepatic MALT lymphoma in the absence of lymphoproliferative disease outside the liver. Serological investigation into the possibility of autoimmune hepatitis was warranted but not conducted due to the patient's financial constraints.
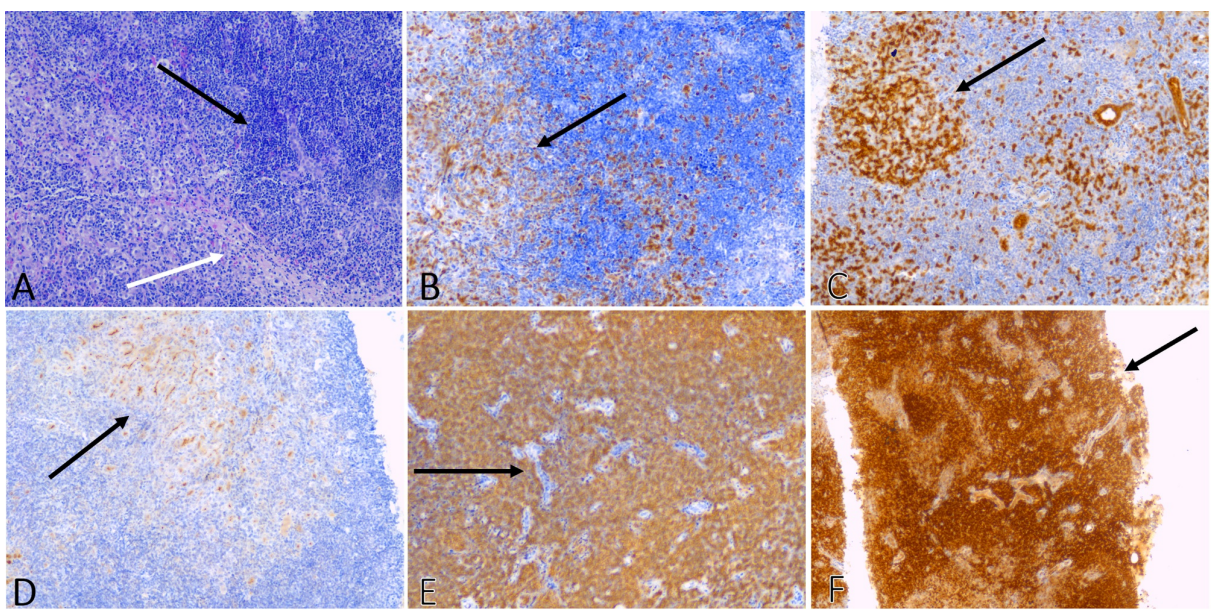

FIGURE 3: Histopathologic analysis of the liver biopsy: image A (H\&E, $x 200$ ) shows dense lymphocytic infiltrate (black arrow) with a vascularized fibrotic septum (white arrow); image B (IHC, x200) shows modest staining for CD3 (black arrow), corresponding to moderate Tcell infiltration; image C (IHC, x40) shows positive staining for CD5 (black arrow), a mantle cell lymphoma marker; image D (IHC, x200) shows modest staining for CD10 (black arrow), thus steering the diagnosis away from HCC, DLBCL, Burkitt lymphoma, and follicular lymphoma; image E (IHC, x200) shows intense staining for CD20, which highlights B-cell infiltration particularly around ducts hepatic ducts 


\section{Cureus}

(black arrow); lastly, image $\mathrm{F}$ (IHC, $\mathrm{x40}$ ) shows diffuse staining for BCL2 (black arrow).

H\&E: hematoxylin and eosin; CD: cluster of differentiation; IHC: immunohistochemistry; HCC: hepatocellular carcinoma; DLBCL: diffuse large B-cell lymphoma; BCL2: B-cell lymphoma 2.

Throughout the hospitalization, renal function and cutaneous lesions improved under therapy with loop diuretics, high-dose glucocorticoids, and the evolution of renal function is summarized in Figure 4. Liver enzymes also improved and normalized to near normal values by the time of discharge.

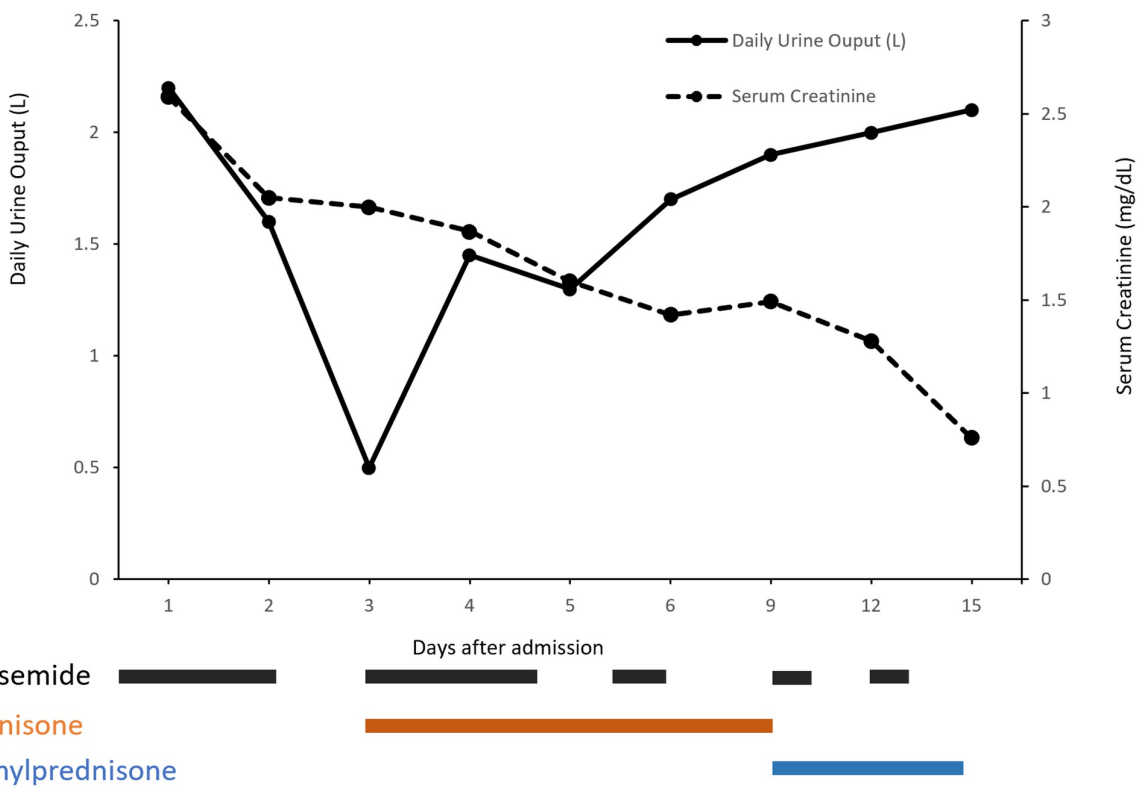

FIGURE 4: Evolution of the patient's renal function* and the accompanying therapy over 15 days of hospitalization at our department.

*Glomerular filtration rate values were not included as renal function was not stable.

The patient was also referred to oncology and promptly started on rituximab, cyclophosphamide, doxorubicin, vincristine, and prednisolone (R-CHOP regimen). Due to the negative serology, the suspicion for an underlying chronic viral hepatitis infection was raised in hindsight, and polymerase chain reaction tests to assess for viral load were not conducted before the initiation of chemotherapy. Three months later the patient was re-admitted with fulminant hepatitis, which proved fatal. There was high viral load of HBV and hepatitis D virus, despite negative serology for the surface antigen. It was unclear at which point he contracted the infection at this time.

\section{Discussion}

We presented a patient with AKI, sensorimotor neuropathy, cutaneous ulcero-necrotic lesions secondary to type I CG that was caused by a primary hepatic MALT lymphoma. Néel et al. described the clinical characteristics of 36 patients with type I CG and the most common features of the disease [5]. Curiously, they identified 227 patients in whom type I cryoglobulins were detectable, but the majority of their patients (191) were asymptomatic, meaning approximately $85 \%$ of patients did not have any manifestations of this disease. The clinical features of type I CG from their study, and whether or not these findings were present in our patient, are summarized in Table 2. Cutaneous and vasomotor findings (defined as Raynaud phenomenon or paroxysmal acrocyanosis) were consistently the most common findings in symptomatic patients in their study. 


\section{Cureus}

\begin{tabular}{|c|c|c|c|}
\hline Signs and symptoms & Prevalence in IgG type I CG & Prevalence in IgM type I CG & Present in our patient \\
\hline Sensorimotor neuropathy & $36 \%$ & $52 \%$ & Yes \\
\hline Nephropathy & $55 \%$ & $20 \%$ & Yes \\
\hline Vasomotor signs & $18 \%$ & $36 \%$ & No \\
\hline Milld skin lesions (purpura) & $64 \%$ & $36 \%$ & No \\
\hline Severe skin lesions ${ }^{\star}$ & $55 \%$ & $8 \%$ & Yes \\
\hline Arthralgia & $36 \%$ & $12 \%$ & No \\
\hline
\end{tabular}

\section{TABLE 2: Common clinical features of symptomatic patients with type I CG.}

CG: cryoglobulinemia; Ig: immunoglobulin.

*Severe skin lesions were defined by infarction, ulceration, and necrosis.

We maintain high index of suspicion that the cutaneous lesions of our patient are due to cryoglobulinemic vasculitis. With the associated symptoms of AKI, neuropathy, and hepatic lesions, four types of vasculitis per the Chapel Hill classification could be considered: cryoglobulinemic vasculitis, lupus vasculitis, hepatitis virus-associated, and cancer-associated vasculitis [6]. Negative viral serology and normal titers of antinuclear and anti-double stranded deoxyribonucleic acid (DNA) antibodies effectively rule out lupus and hepatitis virus-associated vasculitis. Although it has been described that many solid cancers (including lymphoma) can act as vasculitis-triggering factors, due to the clinical picture, elevated cryoglobulins, and statistical likelihood, cryoglobulinemic vasculitis is a more probable diagnosis [7].

To further explore the association between type I CG and renal involvement, a search of the PubMed and Scopus databases was conducted by using different combinations of keywords "type I cryoglobulinemia," "cryoglobulinemic glomerulonephritis," "clinical presentation," and "clinical characteristics" to identify relevant studies. The keywords were identified via the medical subject heading $(\mathrm{MeSH})$ terms or within the title or abstract. Case reports/series and studies that evaluated all types (type I with type II and III) of CG were excluded, as were studies that evaluated type I CG as caused by an isolated pathology (e.g., multiple myeloma). We identified five studies that fit per our selection strategy, and the results are presented in Table $3[5,8-11]$. 


\section{Cureus}

\begin{tabular}{|c|c|c|c|c|c|}
\hline $\begin{array}{l}\text { Author } \\
\text { and year }\end{array}$ & $\begin{array}{l}\text { Total } \\
\text { patients and } \\
\text { mean age }\end{array}$ & $\begin{array}{l}\text { Number of cases } \\
\text { with renal } \\
\text { involvement }\end{array}$ & $\begin{array}{l}\text { Serum } \\
\text { creatinine and } \\
\text { proteinuria }\end{array}$ & $\begin{array}{l}\text { Number of cases with renal } \\
\text { involvement and conducted } \\
\text { biopsy }\end{array}$ & Type of renal involvement ${ }^{\star}$ \\
\hline $\begin{array}{l}\text { Terrier et } \\
\text { al., } 2013 \\
\text { [9] }\end{array}$ & $\begin{array}{l}64 \text { patients, } \\
65.4 \text { years }\end{array}$ & 19 & $\begin{array}{l}\text { NA and } 1.12 \\
\text { g/day }\end{array}$ & 18 & $\begin{array}{l}\text { MPGN (17), GN with isolated C3 } \\
\text { deposits (1) }\end{array}$ \\
\hline $\begin{array}{l}\text { Néel et } \\
\text { al., 2014 } \\
{[5]}\end{array}$ & $\begin{array}{l}36 \text { patients, } \\
63.0 \text { years }\end{array}$ & 11 & $\begin{array}{l}3.55 \mathrm{mg} / \mathrm{dL} \\
\text { and } 4 \mathrm{~g} / \mathrm{day}\end{array}$ & 10 & $\begin{array}{l}\text { MPGN (7), thrombotic } \\
\text { microangiopathy (2), } \\
\text { lymphomatous infiltration (1) }\end{array}$ \\
\hline $\begin{array}{l}\text { Harel et } \\
\text { al., 2014 } \\
\text { [11] }\end{array}$ & $\begin{array}{l}64 \text { patients, } \\
62.0 \text { years }\end{array}$ & 13 & $\begin{array}{l}\text { NA and }>1 \\
g / \text { day }\end{array}$ & 9 & $\begin{array}{l}\text { MPGN (7), glomerular capillary } \\
\text { congestion (1) }\end{array}$ \\
\hline $\begin{array}{l}\text { Sidana et } \\
\text { al., } 2017 \\
\text { [10] }\end{array}$ & $\begin{array}{l}102 \text { patients, } \\
59.0 \text { years }\end{array}$ & 14 & NA & 13 & $\begin{array}{l}\text { MPGN (9), proliferative GN (3), } \\
\text { thrombotic microangiopathy (1) }\end{array}$ \\
\hline $\begin{array}{l}\text { Zhang et } \\
\text { al., 2020 } \\
\text { [8] }\end{array}$ & $\begin{array}{l}45 \text { patients, } \\
61.0 \text { years }\end{array}$ & 7 & $\begin{array}{l}\text { NA and }>0.5 \\
g / \text { day }\end{array}$ & 4 & $\begin{array}{l}\text { MPGN (3), endocapillary } \\
\text { proliferative GN (1) }\end{array}$ \\
\hline
\end{tabular}

TABLE 3: Summary of studies that described renal involvement in patients with type I CG.

MPGN: membranoproliferative glomerulonephritis; GN: glomerulonephritis; NA: not applicable.

*For some studies, results of all of the biopsies were not included.

The studies were comprised of 311 patients with type I CG, 64 (20.6\%) of which were reported to have renal involvement, consistent with other reports in literature [12]. A total of 54 (17.3\%) patients who had renal involvement also underwent renal biopsy for diagnosis and evaluation of disease activity. Three studies (31 patients total) made the distinction between IgG and IgM isotypes of type I CG $[5,8,11]$. Some variables, like serum creatinine and proteinuria, were not uniformly defined by all studies. MPGN was the predominant type of renal involvement, followed by proliferative GN (and its subtypes, namely, endocapillary proliferative GN or C3 glomerulopathy) and is consistent with the literature, where MPGN is reported to account for 70\%90\% of GN cases in patients with CG [13]. Furthermore, of these 311 patients, only three presented with AKI and nephrotic range proteinuria. The majority of patients presented with delayed disease and paucity of extrarenal manifestations, displaying the importance of regular monitoring of renal function to detect indolent renal function decline. Unfortunately, because a renal biopsy was not done, we can only speculate regarding the cause of the AKI in our patient - we believe the most likely cause is tubular obstruction by light chains, as cast nephropathy associated with a gastric IgM-secreting MALT lymphoma has been described [14]. Cryoglobulinemic MPGN is statistically more likely, but our patient lacked the hallmark features of overt hematuria and/or proteinuria, making it more difficult to argue for this diagnosis.

The three most common lymphoproliferative causes for IgG type I CG are MGUS $(n=31)$, MM $(n=16)$, B-NHL $(n=5)$, while for IgM type I CG they are WM $(n=25)$, MGUS $(n=17)$, B-NHL $(n=8)$, and this information is summarized in Figure 5. These values were calculated from two studies, which divided their patients (109 total) according to the predominant Ig isotypes and reported the associated lymphoproliferative disorders discovered at diagnosis $[8,11]$. 


\section{Cureus}

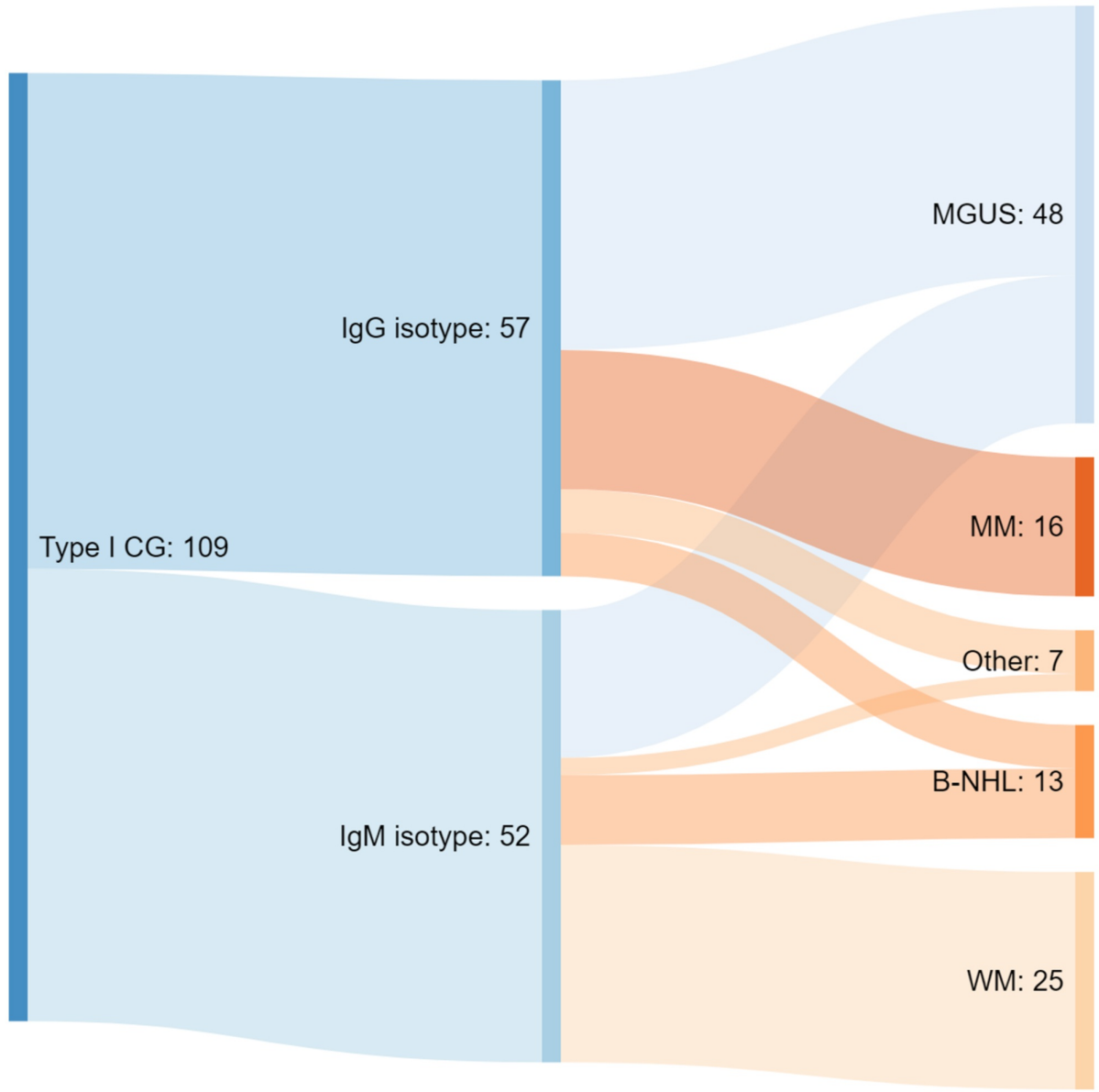

\section{FIGURE 5: Etiologies of type I CG divided by predominent isotype.}

CG: cryoglobulinemia; IgG: immunoglobulin G; IgM: immunoglobulin M; MGUS: monoclonal gammopathy of undetermined significance; MM: multiple myeloma, B-NHL: B-cell non-Hogdkin lymphoma; WM: Waldenstrom macroglobulinemia.

*Other causes included chronic lymphocytic leukemia, cold agglutinin disease, and amyloidosis.

B-NHL is an uncommon cause of type I CG and, in our case, represents another unique aspect, being a MALT lymphoma localized to the liver that is extremely rare - only 67 cases have been reported in literature [15]. Furthermore, the diagnosis of MALT lymphoma was accidental, without directly or indirectly influencing the symptoms for which the patient presented to the hospital. Response to glucocorticoids in our patient was excellent, with serum creatinine improving from a peak of $2.59 \mathrm{mg} / \mathrm{dL}$ to $0.76 \mathrm{mg} / \mathrm{dL}$ over a two-week period. Estimated glomerular filtration rate also improved from $25 \mathrm{~mL} / \mathrm{min}$ to $61 \mathrm{~mL} / \mathrm{min}$. Several cases of biopsyproven cryoglobulinemic MPGN associated with MALT lymphoma have been described and authors noted similar recovery rates of renal function, although over a longer four-week hospital course [16,17]. The faster rate of recovery of renal function is the second reason why tubular obstruction can be considered as the cause of AKI.

Lastly, we would like to draw attention to the occult HBV infection that led to the death of the patient. Screening for the HBV surface antigen (HBsAg) was done at admission and subsequently on a monthly basis it was repeatedly negative. The rates of occult $\mathrm{HBV}$ infection (i.e., HBsAg negative) were found to range from $6.1 \%$ to $11.0 \%$ in patients with B-NHL, thus posing a significant risk of reactivation during immunosuppressive treatment $[18,19]$. Elbedewy et al. noted a $6.94 \%$ reactivation rate of occult $\mathrm{HBV}$ in their patients upon initiation of chemotherapy for B-NHL, which negatively impacted survival [19]. The chronic inflammatory infiltrate on liver biopsy in our patient was a clue that the patient may have been positive for HBV. He was also not vaccinated for HBV but did not receive blood transfusions or underwent surgery. Although prophylactic treatment is not recommended, screening with quantitative HBV DNA in patients with lymphoma prior to chemotherapy may be warranted, especially if the immunosuppressive regimen involves biologic therapy [20].

\section{Conclusions}


Renal involvement in patients with type I CG is relatively common, especially in the IgG isotype of the disease. The most common cause of renal impairment is MPGN with a gradual, indolent onset and a paucity of extrarenal manifestations - regular screening for renal function is important in this patient subset. In rare cases, such as ours, cryoglobulinemic MPGN can manifest as AKI, and other clinical findings, such as cutaneous lesions and peripheral sensorimotor neuropathy, should raise suspicion for the disease. Clinicians should expect acceptable recovery of renal function under treatment with glucocorticoids. Unfortunately, virtually all cases of type I CG are caused by an underlying lymphoproliferative disorder, and a search for a cause should promptly be started. If the diagnosis is a B-HNL, screening via quantitative HBV DNA may be warranted, even in context of negative $\mathrm{HBsAg}$, to exclude the possibility of occult HBV reactivation and avoid fulminant hepatitis.

\section{Additional Information \\ Disclosures}

Human subjects: Consent was obtained by all participants in this study. Conflicts of interest: In compliance with the ICMJE uniform disclosure form, all authors declare the following: Payment/services info: All authors have declared that no financial support was received from any organization for the submitted work. Financial relationships: All authors have declared that they have no financial relationships at present or within the previous three years with any organizations that might have an interest in the submitted work. Other relationships: All authors have declared that there are no other relationships or activities that could appear to have influenced the submitted work.

\section{References}

1. Brouet JC, Clauvel JP, Danon F, et al.: Biologic and clinical significance of cryoglobulins. A report of 86 cases. Am J Med. 1974, 57:775-788. 10.1016/0002-9343(74)90852-3

2. Desbois AC, Cacoub P, Saadoun D: Cryoglobulinemia: an update in 2019. Joint Bone Spine. 2019, 86:707713. 10.1016/j.jbspin.2019.01.016

3. Roccatello D, Saadoun D, Ramos-Casals M, et al.: Cryoglobulinaemia. Nat Rev Dis Primers. 2018, 4:11. 10.1038/s41572-018-0009-4

4. Ramos-Casals M, Stone JH, Cid MC, et al.: The cryoglobulinaemias. Lancet. 2012, 379:348-360. 10.1016/s0140-6736(11)60242-0

5. Néel A, Perrin F, Decaux O, et al.: Long-term outcome of monoclonal (type 1) cryoglobulinemia . Am J Hematol. 2014, 89:156-161. 10.1002/ajh.23608

6. Jennette JC, Falk RJ, Andrassy K, et al.: Nomenclature of systemic vasculitides. Proposal of an international consensus conference. Arthritis Rheum. 1994, 37:187-192. 10.1002/art.1780370206

7. Fain O, Hamidou M, Cacoub P, et al.: Vasculitides associated with malignancies: analysis of sixty patients . Arthritis Rheum. 2007, 57:1473-1480. 10.1002/art.23085

8. Zhang LL, Cao XX, Shen KN, et al.: Clinical characteristics and treatment outcome of type I cryoglobulinemia in Chinese patients: a single-center study of 45 patients. Ann Hematol. 2020, 99:17351740. 10.1007/s00277-020-04123-1

9. Terrier B, Karras A, Kahn JE, et al.: The spectrum of type I cryoglobulinemia vasculitis: new insights based on 64 cases. Medicine. 2013, 92:61-68. 10.1097/md.0b013e318288925c

10. Sidana S, Rajkumar SV, Dispenzieri A, et al.: Clinical presentation and outcomes of patients with type 1 monoclonal cryoglobulinemia. Am J Hematol. 2017, 92:668-673. 10.1002/ajh.24745

11. Harel S, Mohr M, Jahn I, et al.: Clinico-biological characteristics and treatment of type 1 monoclonal cryoglobulinaemia: a study of 64 cases. Br J Haematol. 2015, 168:671-678. 10.1111/bjh.13196

12. Cacoub P, Comarmond C, Domont F, et al.: Cryoglobulinemia vasculitis. Am J Med. 2015, 128:950-955. 10.1016/j.amjmed.2015.02.017

13. Chen YP, Cheng H, Rui HL, et al.: Cryoglobulinemic vasculitis and glomerulonephritis: concerns in clinical practice. Chin Med J (Engl). 2019, 132:1723-1732. 10.1097/cm9.0000000000000325

14. Luan H, Wang C, Xing X, et al.: Cast nephropathy associated with monoclonal immunoglobulin m-secreting mucosa-associated lymphoid tissue B-cell lymphoma. Clin Nephrol. 2019, 91:380-385. 10.5414/cn109682

15. Dong S, Chen L, Chen Y, et al.: Primary hepatic extranodal marginal zone B-cell lymphoma of mucosaassociated lymphoid tissue type: a case report and literature review. Medicine (Baltimore). 2017, 96:6305. 10.1097/md.0000000000006305

16. Ha AY, Noronha N, Gleason P, et al.: Cryoglobulinemic membranoproliferative glomerulonephritis associated with mucosa-associated lymphoid tissue lymphoma treated with rituximab. Clin Nephrol Case Stud. 2016, 4:1-4. 10.5414/cncs 108740

17. Yeo SC, Chuah KL, Lee HY, et al.: An unusual case of glomerulonephritis in a patient with non-Hodgkin mucosal associated lymphoid tissue (malt) B-cell lymphoma. BMC Nephrol. 2013, 14:158. 10.1186/14712369-14-158

18. Chen MH, Hsiao LT, Chiou TJ, et al.: High prevalence of occult hepatitis B virus infection in patients with B cell non-Hodgkin's lymphoma. Ann Hematol. 2008, 87:475-480. 10.1007/s00277-008-0469-9

19. Elbedewy TA, Elashtokhy HE, Rabee ES, et al.: Prevalence and chemotherapy-induced reactivation of occult hepatitis B virus among hepatitis B surface antigen negative patients with diffuse large B-cell lymphoma: significance of hepatitis B core antibodies screening. J Egypt Natl Canc Inst. 2015, 27:11-18. 10.1016/j.jnci.2015.01.004

20. Mastroianni CM, Lichtner M, Citton R, et al.: Current trends in management of hepatitis B virus reactivation in the biologic therapy era. World J Gastroenterol. 2011, 17:3881-3887. 10.3748/wjg.v17.i34.3881 